\title{
Davallia mariesii Moore Improves FceRI-Mediated Allergic Responses in the Rat Basophilic Leukemia Mast Cell Line RBL-2H3 and Passive Cutaneous Anaphylaxis in Mice
}

\author{
Hyun Ju Do, Tae Woo Oh, Ju Hye Yang, Kwang Il Park, and Jin Yeul Ma \\ Korean Medicine (KM)-Application Center, Korea Institute of Oriental Medicine (KIOM), 70 Cheomdan-ro, Dong-gu, Daegu 41062, \\ Republic of Korea
}

Correspondence should be addressed to Kwang Il Park; kipark@kiom.re.kr and Jin Yeul Ma; jyma@kiom.re.kr

Received 10 July 2017; Revised 18 September 2017; Accepted 2 October 2017; Published 19 October 2017

Academic Editor: Sandra Helena Penha Oliveira

Copyright (c) 2017 Hyun Ju Do et al. This is an open access article distributed under the Creative Commons Attribution License, which permits unrestricted use, distribution, and reproduction in any medium, provided the original work is properly cited.

\begin{abstract}
Davallia mariesii Moore (Drynaria rhizome extract (DRE)) is widely known for its efficacy in treating inflammation, arteriosclerosis, and bone injuries. This study evaluated whether treatment with DRE inhibited FceRI-mediated allergic responses in the RBL-2H3 mast cells and investigated the early- and late-phase mechanisms by which DRE exerts its antiallergic effects. IgE anti-DNP/DNP-HSA-sensitized RBL-2H3 mast cells were tested for cytotoxicity to DRE, followed by the assessment of $\beta$-hexosaminidase release. We measured the amounts of inflammatory mediators (e.g., histamine, PGD ${ }_{2}$, TNF- $\alpha$, IL-4, and IL-6) and examined the expression of genes involved in arachidonate and FceRI signaling pathways. In addition, we confirmed the antiallergic effects of DRE on passive cutaneous anaphylaxis (PCA) in mice. DRE inhibited RBL$2 \mathrm{H} 3$ mast cell degranulation and production of allergic mediators in them. In early allergic responses, DRE reduced expression of FceRI signaling-related genes (e.g., Syk, Lyn, and Fyn) and extracellular signal-regulated kinase phosphorylation in mast cells. In late allergic responses, $\mathrm{DRE}$ reduced $\mathrm{PGD}_{2}$ release and $\mathrm{COX}-2$ expression and $c \mathrm{PLA}$ phosphorylation in FceRI-mediated mast cells. Lastly, 250-500 mg/kg DRE significantly attenuated the IgE-induced PCA reaction in mice. These findings provide novel information on the molecular mechanisms underlying the antiallergic effects of DRE in FceRImediated allergic responses.
\end{abstract}

\section{Introduction}

Allergies have become a worldwide clinical health problem, and their incidence is rapidly increasing due to various factors [1]. Allergic responses include itching, anaphylaxis, asthma, rhinitis, conjunctivitis, angioedema, urticaria, eczema, eosinophilic disorders (including eosinophilic esophagitis), and drug allergies $[2,3]$. The basic treatment for allergies includes avoiding allergens and taking antihistamines, steroids, or immunosuppressants [4]. Many drugs derived from chemical compounds have been developed to treat allergies, but in some cases, they induce side effects or exhibit low efficacy [5]. More recently, to address these problems, natural compounds that regulate allergic reactions have been studied [6]. Davallia mariesii Moore, known as Drynaria rhizome (DR) ("gol-se-bo" in Korean and "gu-sui-bu" in Chinese), is a traditional Korean and Chinese medicine known for its efficacy in treating inflammation, osteoporosis, traumatic brain injury, and arteriosclerosis $[7,8]$. It is commonly used for treating orthopedic disorders and has been claimed to have therapeutic effects on bone healing [9]. In addition, a few studies have reported that DR inhibits the development of atopic dermatitis-like lesions in a house dust mite antigen-induced atopic dermatitis animal model [10]. However, the cellular signaling mechanisms underlying its antiallergic effects have not been studied.

Mast cells, which are rich in granules in their cytoplasm, are found in body areas, such as the skin surface, the mucosa of the gastrointestinal tract, serous membranes, and in the vicinity of lymphatic vessels and blood vessels, that come in 
contact with external stimuli. IgE antibodies, compound $48 / 80$, protein kinase C activator, and calcium ionophores have been reported to induce mast cell degranulation $[11,12]$. In particular, the allergen IgE-FceRI complex, formed by binding of IgE to FceRI and expressed on cellular surfaces, triggers early and late allergic responses and chronically prolongs inflammation by secreting chemical mediators and cytokines [6]. FceRI, a receptor expressed on the cell membranes of mast cells, comprises $\alpha$ and $\beta$ subunits and two $\gamma$ subunits. The $\alpha$ chain is involved in extracellular binding of $\operatorname{IgE}$ to antigens, whereas the $\beta$ and $\gamma$ chains mediate intracellular signaling [13]. Histamine derived from histidine decarboxylase is primarily released upon mast cell degranulation, and arachidonic acid is released from phospholipids of the cell membrane by phospholipase A2 $\left(\mathrm{CPLA}_{2}\right)$ [14]. Cyclooxygenase-2 (COX-2) induces the synthesis and secretion of lipid metabolites, such as prostaglandins and leukotrienes, that trigger inflammation and pain [15]. These mediators induce immediate hypersensitivity reactions. Cell signaling begins when Src family kinases phosphorylate the $\beta$ subunits of FceRI receptors in mast cells stimulated by an antigen [16]. Lyn phosphorylates the tyrosine-phosphorylated immunoreceptor tyrosine-based activation motif (ITAM) of FceR, which is a high-affinity IgE receptor. The binding of Syk to phosphorylated ITAMs is regulated by two $\mathrm{SH} 2$ domains; it causes structural changes in Syk, resulting in increased enzymatic activity [17]. Subsequently, other multiple signaling and adaptor molecules, including ERK, PLC $\gamma 1$, and Akt, form Syk-receptor complexes, thereby activating the overall signaling system [18].

In the present study, we hypothesized that DRE influences the phosphorylation of Src family kinases and antiallergic effects, including early- and late-phase reactions, in mast cells, ultimately exerting beneficial effects against IgE-mediated allergies by reducing mast cell degranulation. To test this hypothesis, we examined the effect of DRE supplementation on proinflammatory cytokines, including TNF- $\alpha$, IL-4, and IL-6, in IgE-mediated RBL-2H3 mast cells. Furthermore, we assessed the roles of DRE in the FceRI signaling pathway (e.g., on Syk, Lyn, and Fyn) and the arachidonate signaling pathway (e.g., on COX-2 and $\left.\mathrm{cPLA}_{2}\right)$ as well as its effects on IgE-mediated allergic responses in RBL-2H3 mast cells.

\section{Materials and Methods}

2.1. Chemicals. Rat basophilic leukemia mast cell line RBL-2H3 was obtained from the American Type Culture Collection (Manassas, VA, USA). Minimum essential medium alpha modification (MEM- $\alpha$ medium), Dulbecco's phosphate-buffered saline, fetal bovine serum (FBS), and antibiotics $(100,000$ unit/L penicillamine and $100 \mathrm{mg} / \mathrm{L}$ streptomycin) were purchased from GE Healthcare Life Sciences (HyClone ${ }^{\mathrm{TM}}$, Logan, UT, USA). Dinitrophenyl human serum albumin (DNP-HSA), DNP-immunoglobulin $\mathrm{E}$ (IgE anti-DNP), and dexamethasone were obtained from Sigma-Aldrich (St. Louis, MO, USA). 3-(4,5-Dimethylthiazol-2-yl)-2,5-diphenyltetrazolium bromide (MTT) was purchased from Amresco (Solon, OH, USA). D. mariesii Moore (Drynaria rhizome extract (DRE)) was obtained from Korean Medicine Application Center (Daegu, Korea).

2.2. Preparation of a Water Extract of Drynaria Rhizome. DR was obtained from Yeongcheon hyundai herbal market (Yeongcheon, Korea) and verified by Professor Ki Hwan Bae, Chungnam National University, Republic of Korea. To prepare the DRE, dried DR $(30.0 \mathrm{~g})$ were placed in $1000 \mathrm{~mL}$ distilled water and then extracted by $3 \mathrm{~h}$ of heating at $115^{\circ} \mathrm{C}$ (Gyeongseo Extractor Cosmos-600, Incheon, Korea). Following extraction, the solution was filtered using standard testing sieves $(150 \mu \mathrm{m})$ (Retsch, Haan, Germany). Samples were freeze-dried and stored at $-20^{\circ} \mathrm{C}$ before use. Sample acquisition was $5.2 \mathrm{~g}$, and the yield was $17.5 \%$. The powder of DRE was dissolved in $10 \%$ DMSO solution for all experiments.

2.3. Cell Culture. Rat RBL-2H3 mast cells were grown in MEM- $\alpha$ medium supplemented with $10 \%$ heat-inactivated FBS containing $1 \%$ antibiotics (ABS). Prior to the experiments, $3 \times 10^{5}$ cells were seeded on a six-well plate and grown to confluence for $24 \mathrm{~h}$. At day 2 post-confluence, the medium was replaced with the MEM- $\alpha$ medium (10\% FBS and $1 \%$ ABS) containing IgE anti-DNP $(0.1 \mu \mathrm{g} / \mathrm{mL})$ for $16 \mathrm{~h}$. The medium was replaced with the serum-free medium (MEM- $\alpha$ medium with $1 \%$ FBS and $1 \%$ ABS) containing DRE $(100-500 \mu \mathrm{g} / \mathrm{mL})$ and dexamethasone $(100 \mathrm{nM})$ for $1 \mathrm{~h}$ and then treated with DNP-HSA $(0.1 \mu \mathrm{g} / \mathrm{mL})$ for $4 \mathrm{~h}$ and/or $30 \mathrm{~min}$. The cells were maintained at $37^{\circ} \mathrm{C}$ in a humidified atmosphere of $95 \%$ air and $5 \% \mathrm{CO}_{2}$.

2.4. MTT Assay. DRE was prepared in a $10 \%$ dimethyl sulfoxide (DMSO) solution at a concentration of $100 \mathrm{mg} / \mathrm{mL}$. RBL-2H3 mast cells were tested with increasing concentrations of DRE for $1 \mathrm{~h}$. Cell viability was analyzed after adding $0.5 \mathrm{mg} / \mathrm{mL}$ MTT in each well, followed by incubation for $40 \mathrm{~min}$ at $37^{\circ} \mathrm{C}$. After removing the medium, the cells were lysed with DMSO. Absorbance at $570 \mathrm{~nm}$ wavelength was measured using a microplate reader.

2.5. $N$-Acetyl- $\beta$-d-glucosaminidase ( $\beta$-Hexosaminidase) Release Assay. The culture medium of IgE-sensitized RBL-2H3 mast cells treated with DRE was mixed with $25 \mu \mathrm{L}$ of 4-methylumbellyferyl-N-acetyl- $\beta$-d-glucosaminidase ( $10 \mathrm{mM}$ p-NAG) in sodium citrate buffer $(0.1 \mathrm{M}, \mathrm{pH} 4.5)$ and then incubated for $1 \mathrm{~h}$ at $37^{\circ} \mathrm{C}$, according to the method described by Park et al. [6]. The reaction was stopped by adding sodium carbonate buffer $(0.1 \mathrm{M}, \mathrm{pH} 10.0)$. Absorbance at $405 \mathrm{~nm}$ wavelength was measured using a microplate reader.

2.6. Measurement of Inflammatory Mediators. Histamine, PGD $_{2}$, TNF- $\alpha$, IL-4, and IL- 6 levels in the culture medium of IgE-sensitized RBL-2H3 mast cells treated with DRE were determined using enzyme-linked immunosorbent assay kits, as per the manufacturer's instructions.

2.7. Immunoblot Analysis. The cells were scraped from the plates using RIPA Lysis Buffer (Merck Millipore, Darmstadt, Germany) containing a protease and phosphatase inhibitor 
cocktail (Roche, Basel, Switzerland). After incubation on ice for $30 \mathrm{~min}$, the cell lysates were centrifuged at $14,000 \mathrm{rpm}$ for $20 \mathrm{~min}$ at $4^{\circ} \mathrm{C}$. Proteins were quantified using BCA protein assay (Thermo Scientific, Waltham, MA, USA). The protein lysates were resolved on $10 \%$ sodium dodecyl sulfate polyacrylamide gels and then transferred to a polyvinylidene difluoride membrane. Anti-COX-2, anti-phospho-cPLA, anti-phospho-Lyn, anti-phospho-Syk, anti-phospho-Fyn, anti-phospho-PLC $\gamma 1$, anti-phospho-ERK, anti-phosphoAkt, and anti- $\alpha$-tubulin antibodies (Cell Signaling Technology, Boston, MA, USA) were used to detect COX-2, p-cPLA, p-Lyn, p-Syk, p-Fyn, p-PLC $\gamma 1$, p-ERK, p-Akt, and $\alpha$-tubulin, respectively. $\alpha$-Tubulin was used as protein loading control. Blots were observed using a western blot detection kit (Thermo Scientific, Waltham, MA, USA). Protein bands were quantified using Image Lab software (Bio-Rad Laboratories, Richmond, CA, USA).

2.8. Animals. Male ICR mice ( $n=25 ; 5$ weeks old) were randomly assigned to five groups (all $n=5$ ) after 1 week adaptation period: control group (CTL), IgE anti-DNP/ DNP-HSA group (IgE anti-DNP/DNP-HSA), IgE antiDNP/DNP-HSA treated with $10 \mathrm{mg} / \mathrm{kg}$ dexamethasone group (Dex), IgE anti-DNP/DNP-HSA treated with $250 \mathrm{mg} / \mathrm{kg}$ DRE group (DRE 250), and IgE anti-DNP/DNP-HSA treated with $500 \mathrm{mg} / \mathrm{kg}$ DRE group (DRE 500). DRE was prepared in $0.5 \%$ low-viscosity carboxymethyl cellulose sodium salt (CMC), and CTL and IgE anti-DNP/DNP-HSA groups received equivalent volumes of vehicle ( $0.5 \% \mathrm{CMC})$. The mice were housed under standard laboratory conditions $\left(21^{\circ} \mathrm{C}-24^{\circ} \mathrm{C}\right.$ and $40 \%-60 \%$ humidity) and were maintained at a $12 \mathrm{~h}$ light $/ 12 \mathrm{~h}$ dark cycle (lights on at 8:00), with ad libitum access to food and water. All experiments were approved by the Committee on Animal Experimentation and Ethics of KIOM.

2.9. Passive Cutaneous Anaphylaxis (PCA) in Mice. The PCA reaction was evaluated as previously described [6]. IgE antiDNP $(4 \mu \mathrm{g} / \mathrm{mL})$ was subcutaneously injected into the ears of ICR mice. At day 1, IgE-sensitized mice were administered oral DRE (250 or $500 \mathrm{mg} / \mathrm{kg}$ ) or dexamethasone $(10 \mathrm{mg} / \mathrm{kg})$. One hour later, DNP-HSA (300 $\mu \mathrm{g} / \mathrm{mL})$ containing $1 \%$ Evans blue was injected into the tail veins. After $1 \mathrm{~h}$, the mice were anesthetized with $\mathrm{CO}_{2}$ and tissues from the treated ears were obtained. The Evans blue dye was removed by the ear tissue, which were then incubated with $1 \mathrm{~mL}$ formamide at $63^{\circ} \mathrm{C}$ for $16 \mathrm{~h}$. The mixtures were centrifuged at $17,000 \times \mathrm{g}$ for $10 \mathrm{~min}$ at $4^{\circ} \mathrm{C}$. Absorbance at $620 \mathrm{~nm}$ wavelength was measured using a microplate reader.

2.10. Statistical Analysis. Statistical analysis was performed using GraphPad Prism version 5 (GraphPad Software Inc., San Diego, CA, USA). The results are presented as means \pm SE. Differences between the experimental groups were analyzed using one-way analysis of variance with Bonferroni's post hoc testing and $p<0.05$ as the criterion for significance.

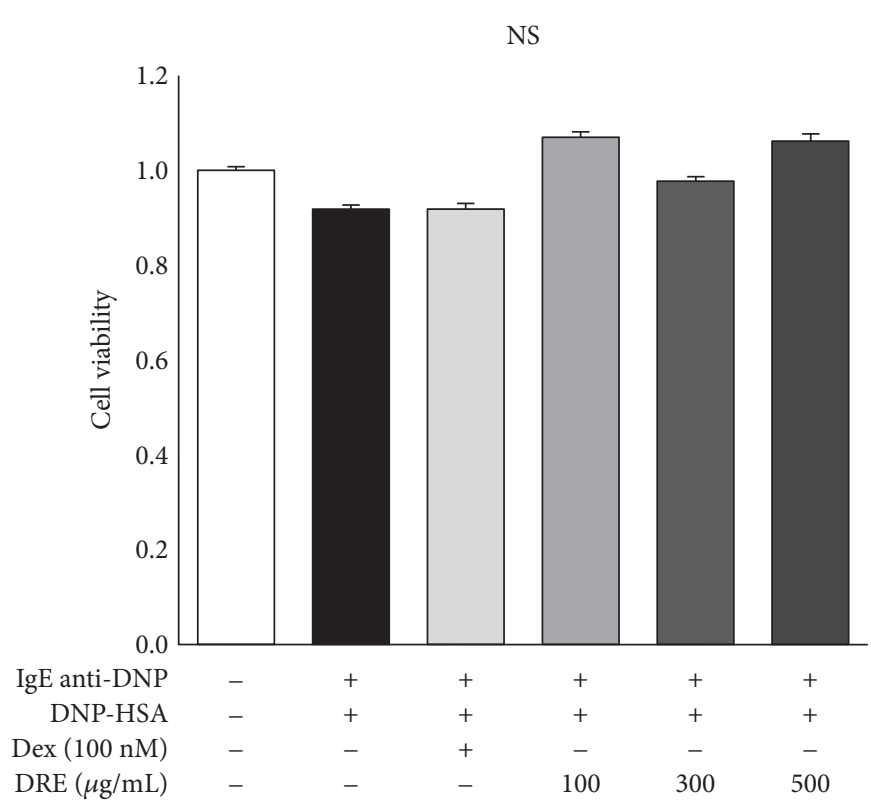

FIGURE 1: Effects of Drynaria rhizome extract (DRE) on cell viability in RBL-2H3 mast cells. RBL-2H3 mast cell viability was analyzed using an MTT assay after treating the cells with DRE (at 100, 300, and $500 \mu \mathrm{g} / \mathrm{mL}$ ) for $1 \mathrm{~h}$ and then treating them with DNP-HSA $(0.1 \mu \mathrm{g} / \mathrm{mL})$ for $4 \mathrm{~h}$. The results are expressed as means $\pm \mathrm{SE}$ calculated from at least three independent experimental results that were tested by analysis of variance with Bonferroni's post hoc testing. NS, not significant at the 0.05 probability level.

\section{Results}

3.1. Effect of DRE on RBL-2H3 Mast Cell Viability. To assess cell viability, RBL-2H3 mast cells were treated with DRE at concentrations of $0,100,300$, and $500 \mu \mathrm{g} / \mathrm{mL}$ (Figure 1). The cell viability was $107 \%$ at a concentration of $100 \mu \mathrm{g} / \mathrm{mL}$ and $98 \%$ and $106 \%$ at concentrations of 300 and $500 \mu \mathrm{g} / \mathrm{mL}$, respectively.

3.2. Effects of DRE on the Inhibition of IgE-Mediated RBL2H3 Mast Cell Degranulation. Mast cells release histamine, cytokines, and other mediators because of degranulation induced by allergic reactions [12]. $\beta$-Hexosaminidase released as a marker of degranulation from mast cells provides a good indicator of the degree of allergic reactions [19]. The effect of DRE on $\beta$-hexosaminidase release was concentration-dependent, with a $44 \%$ decrease at a concentration of $100 \mu \mathrm{g} / \mathrm{mL}$, a $76 \%$ decrease at $300 \mu \mathrm{g} / \mathrm{mL}$ $(p<0.0001)$, and an $84 \%$ decrease at $500 \mu \mathrm{g} / \mathrm{mL}(p<0.0001)$ (Figure 2(a)). These results demonstrated that DRE effectively inhibited IgE-mediated allergic reactions by regulating $\beta$-hexosaminidase release from mast cells.

3.3. Effect of DRE on the Release of Inflammatory Cytokines in RBL-2H3 Mast Cells. We measured the levels of the inflammatory cytokines TNF- $\alpha$, IL- 4 , and IL- 6 in IgE-mediated RBL-2H3 mast cells. DRE at all concentrations significantly reduced the levels of TNF- $\alpha$ released by mast cells (Figure 2(b)); TNF- $\alpha$ levels at DRE concentrations of 100, 


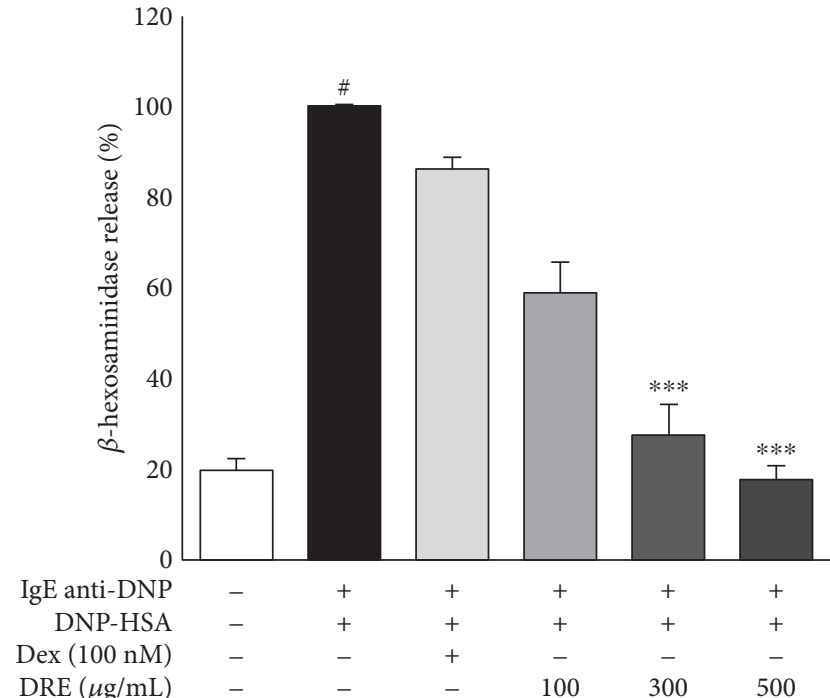

(a)

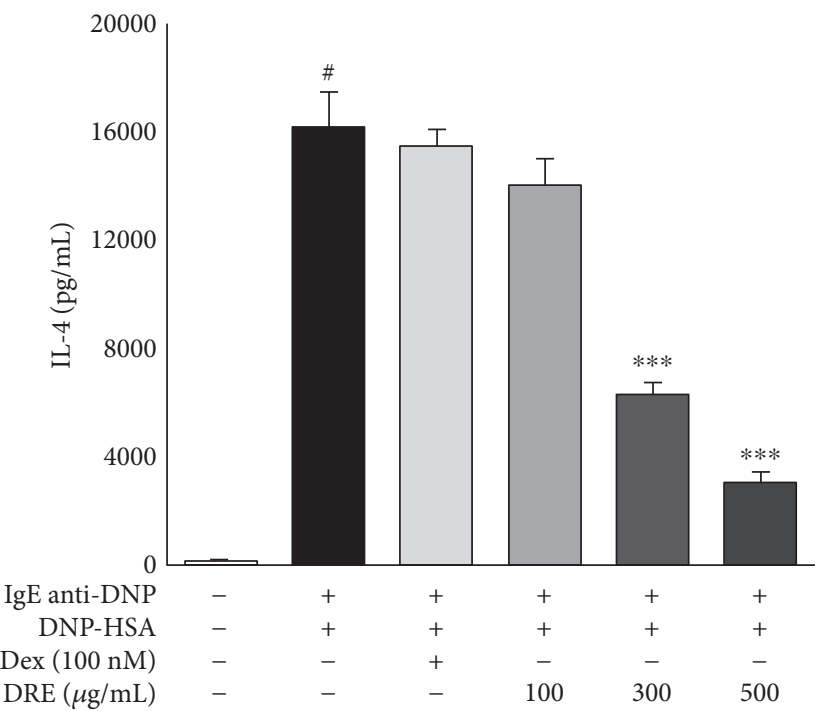

(c)

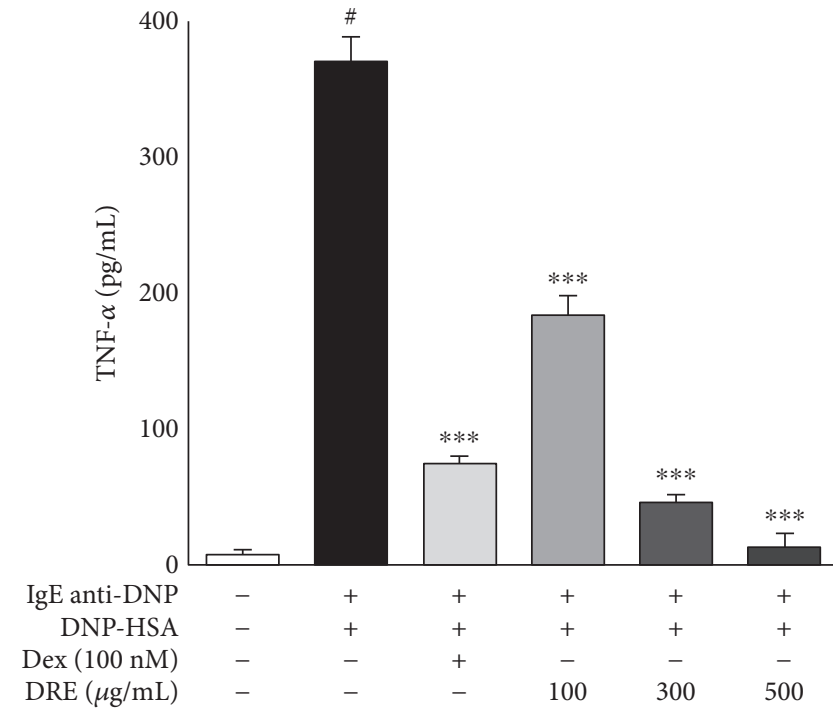

(b)

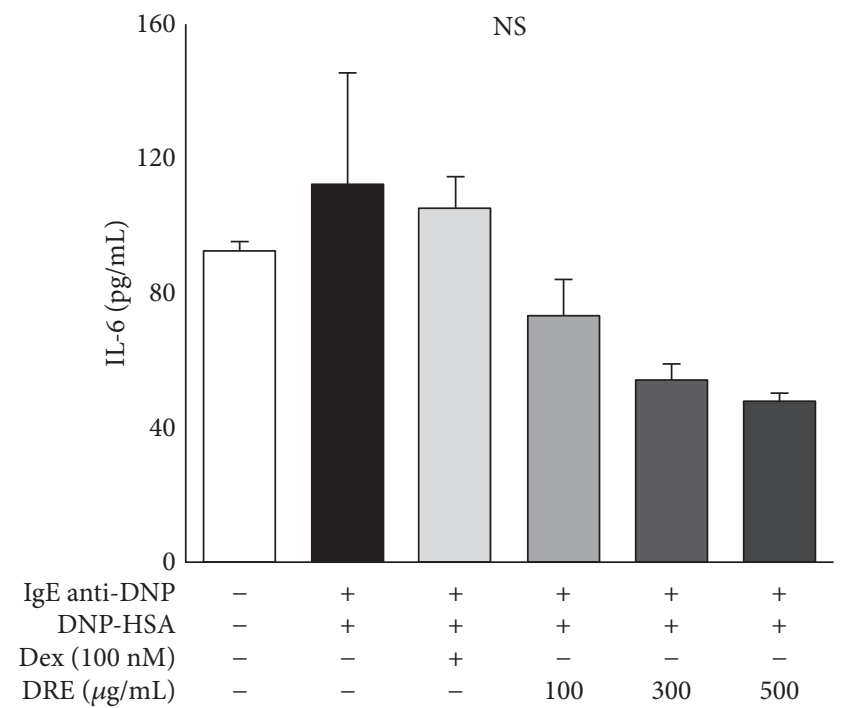

(d)

FIgURE 2: Effect of Drynaria rhizome extract (DRE) at concentrations of 100,300 , and $500 \mu \mathrm{g} / \mathrm{mL}$ on the release of $\beta$-hexosaminidase and proinflammatory cytokines from RBL-2H3 mast cells. (a) $\beta$-Hexosaminidase. (b) TNF- $\alpha$. (c) IL-4. (d) IL-6. The results are expressed as the means $\pm \mathrm{SE}$ of at least three independent experimental results that were tested by analysis of variance with Bonferroni's post hoc testing. ${ }^{\#} p<0.05$, the control group versus the DNP-HSA group; ${ }^{* * *} p<0.0005$, the DNP-HSA group versus the DRE and Dex treatment group. NS, not significant at the 0.05 probability level.

300 , and $500 \mu \mathrm{g} / \mathrm{mL}$ were $181.59 \mathrm{pg} / \mathrm{mL}, 46.01 \mathrm{pg} / \mathrm{mL}$, and $13.01 \mathrm{pg} / \mathrm{mL}$, respectively. Similarly, IL-4 levels were substantially lower in the DRE treatment group than in IgEmediated RBL-2H3 mast cells (Figure 2(c)). IL-6 levels also demonstrated a concentration-dependent reduction across all DRE concentrations (Figure 2(d)).

3.4. Effects of DRE on Late-Phase Reactions in IgE-Mediated RBL-2H3 Mast Cells. PGD2 levels demonstrated a tendency to decrease at all concentrations (Figure 3(a); not significant). We measured the effect of DRE on the arachidonate signaling pathway by examining COX-2 and p-cPLA 2 activation in IgE anti-DNP/DNP-HSA-activated RBL-2H3 mast cells. We observed a decreasing trend in the COX-2 and p-cPLA protein levels following CRE treatment (Figure 3(b)).

3.5. Effects of DRE on Early-Phase Reactions via the FceRI Signaling Pathway in RBL-2H3 Mast Cells. We investigated whether DRE influenced the activation of Src tyrosine kinases in IgE anti-DNP/DNP-HSA-activated RBL-2H3 mast cells. We added varying concentrations of DRE to IgE anti-DNP/DNP-HSA-activated RBL-2H3 mast cells and found that DRE inhibited IgE-mediated histamine release from $\mathrm{RBL}-2 \mathrm{H} 3$ mast cells in a concentrationdependent manner (with 26\%, 28\%, and 33\% inhibition at $100,250$, and $500 \mu \mathrm{g} / \mathrm{mL}$, resp.; Figure $4(\mathrm{a}))$. We observed 


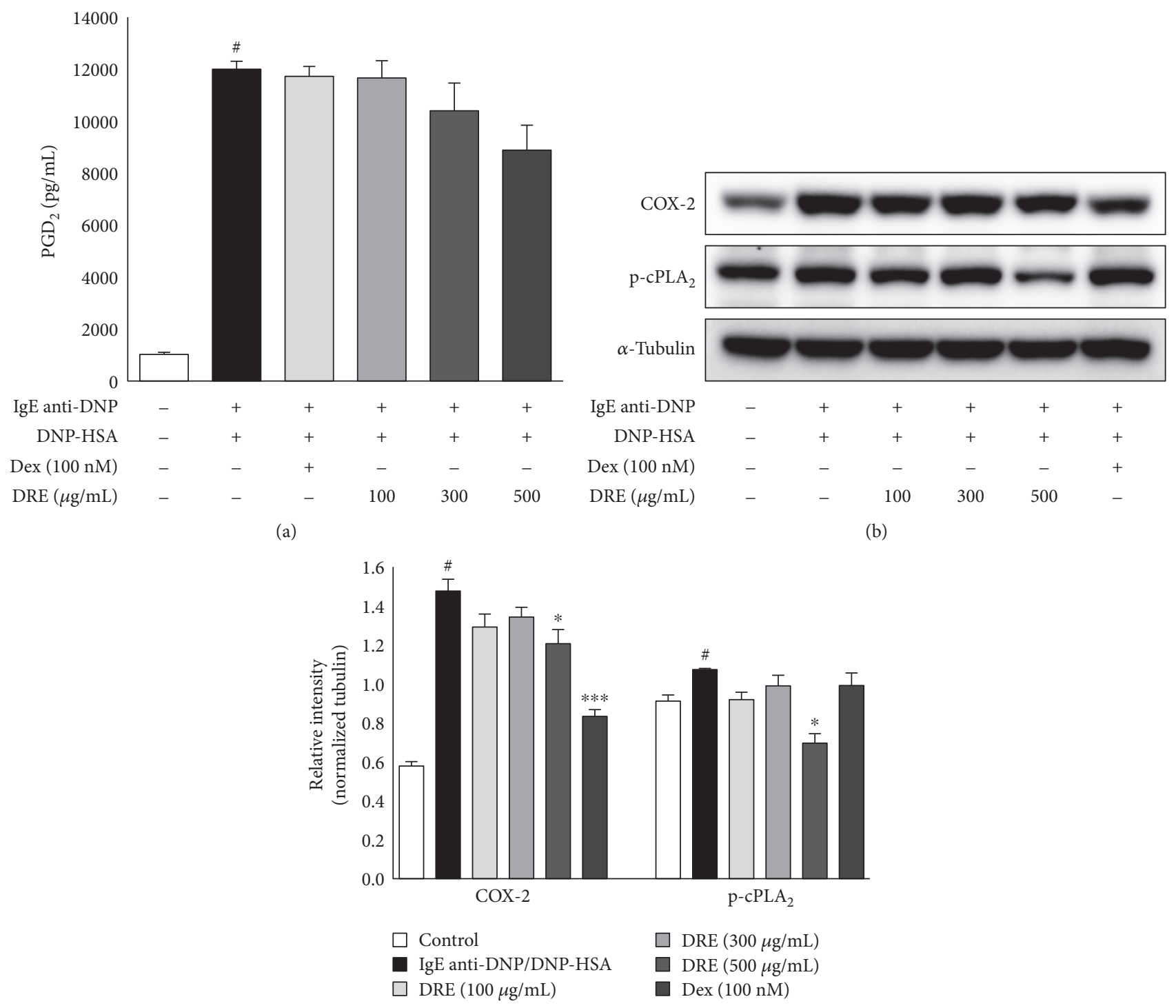

(c)

Figure 3: Effect of Drynaria rhizome extract (DRE) on the expression of COX-2 and p-cPLA 2 genes in RBL-2H3 mast cells. The cells were treated with DRE for $1 \mathrm{~h}$ and then treated with DNP-HSA $(0.1 \mu \mathrm{g} / \mathrm{mL})$ for $4 \mathrm{~h}$. (a) $\mathrm{PGD}_{2}$ levels in the culture medium of IgE-sensitized RBL-2H3 mast cells treated with DRE. (b) Immunoblot analysis performed with anti-COX-2 and p-cPLA ${ }_{2}$ antibodies. $\alpha$-Tubulin was used as protein loading control. Results are expressed as means $\pm \mathrm{SE}$ of at least five independent experimental results that were tested by analysis of variance with Bonferroni's post hoc testing; ${ }^{*} p<0.05$, the control group versus the DNP-HSA group; ${ }^{*} p<0.05$ and ${ }^{* * *} p<0.0005$, the DNP-HSA group versus the DRE and Dex treatment-group.

a decreasing trend in the levels of the phosphorylated form of Lyn protein following DRE treatment (Figure 4(b)). DRE substantially decreased the levels of the phosphorylated form of Syk protein. However, it had no effect on the levels of the phosphorylated from of Fyn protein. The phosphorylation of ERK, a mitogen-activated protein kinase, was reduced by $100 \mu \mathrm{g} / \mathrm{mL}$ at a concentration of DRE. Akt phosphorylation and PLC $\gamma 1$ phosphorylation were reduced by DRE in a concentration-dependent manner. These results demonstrated that DRE activates the FceRI signaling pathway in IgE anti-DNP/DNP-HSA-activated RBL-2H3 mast cells.
3.6. Effect of DRE on Allergic Responses in the PCA Model. We examined the effect of DRE in an animal PCA model representing early-phase allergic responses [6, 20]. The concentration of Evans blue significantly increased from $2.98 \pm 0.29 \mu \mathrm{g} /$ ear in the CTL group to $22.77 \pm 2.29 \mu \mathrm{g} /$ ear in the IgE anti-DNP/DNP-HSA group with the PCA reaction $(p<0.0005)$. Concentrations of Evans blue were significantly lower in the DRE 250 group $(13.0 \pm 2.28 \mu \mathrm{g} /$ ear, $p<0.05)$ and the DRE 500 group $(14.58 \pm 3.28 \mu \mathrm{g} / \mathrm{ear}, p<0.05)$ than in the IgE anti-DNP/DNP-HSA group, but no significant difference was observed between the Dex and IgE anti-DNP/DNP-HSA groups $(19.20 \pm 2.20 \mu \mathrm{g} /$ ear) (Figure 5). 


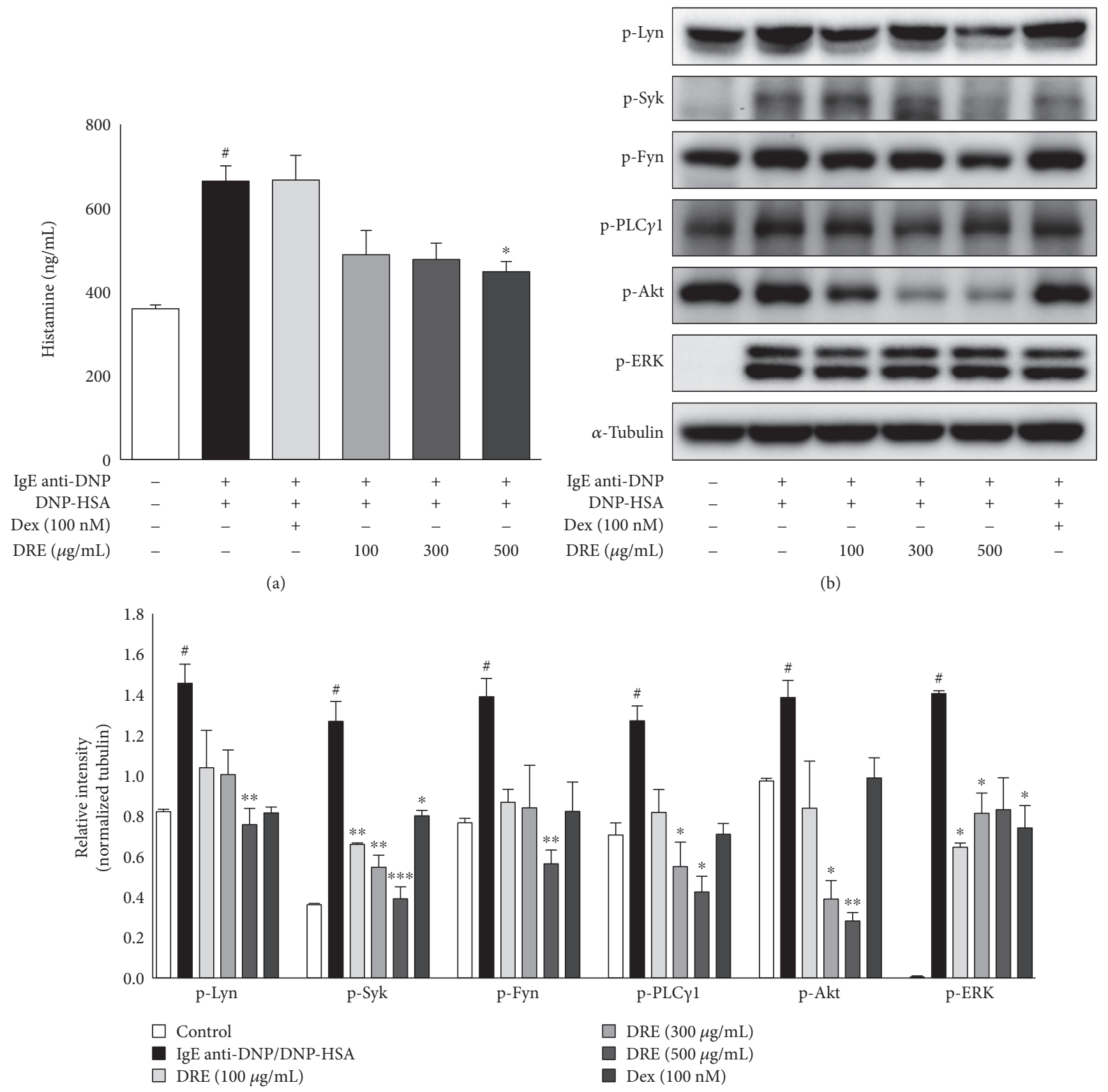

(c)

FIGURE 4: Effect of Drynaria rhizome extract (DRE) on the expression of Src family kinase genes in RBL-2H3 mast cells. The cells were treated with DRE for $1 \mathrm{~h}$ and then treated with DNP-HSA $(0.1 \mu \mathrm{g} / \mathrm{mL})$ for $30 \mathrm{~min}$. (a) Histamine levels in the culture medium of IgE-sensitized RBL-2H3 mast cells treated with DRE. (b) Immunoblot analysis performed with anti-p-Syk, anti-p-Lyn, anti-p-Fyn, anti-p-PLC $\gamma 1$, anti-p-ERK, and anti-p-Akt antibodies. $\alpha$-Tubulin was used as protein loading control. Results are expressed as means \pm SE of at least five independent experimental results that were tested by analysis of variance with Bonferroni's post-hoc testing; ${ }^{*} p<0.05$, the control group versus the DNP-HSA group; ${ }^{*} p<0.05,{ }^{* *} p<0.005$, and ${ }^{* * *} p<0.0005$, the DNP-HSA group versus the DRE and Dex treatment-group.

\section{Discussion}

Mast cells are the main model for studies on inflammatory and allergic diseases, such as asthma, allergic rhinitis, tissue modification, and rheumatoid arthritis [21]. Their most important features are the presence of a high number of granules within them and the chemical mediators that form crystals. Mast cells express FceRI receptors on their cell surface; when antigens cross-link with IgE bound to this receptor, activation begins and degranulation proceeds [22]. It is well known that the rat basophilic leukemia cell line $\mathrm{RBL}-2 \mathrm{H} 3$ plays a role in the mast cell model and 


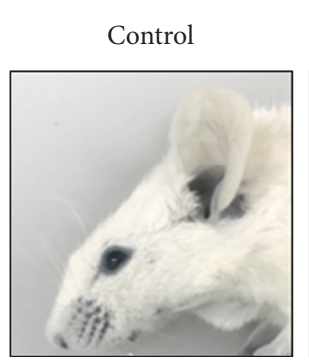

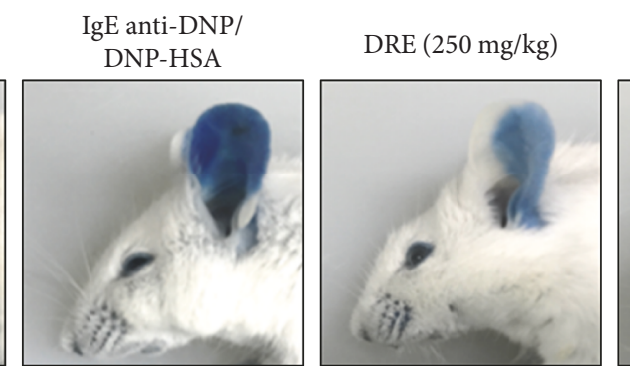

$\operatorname{DRE}(500 \mathrm{mg} / \mathrm{kg})$
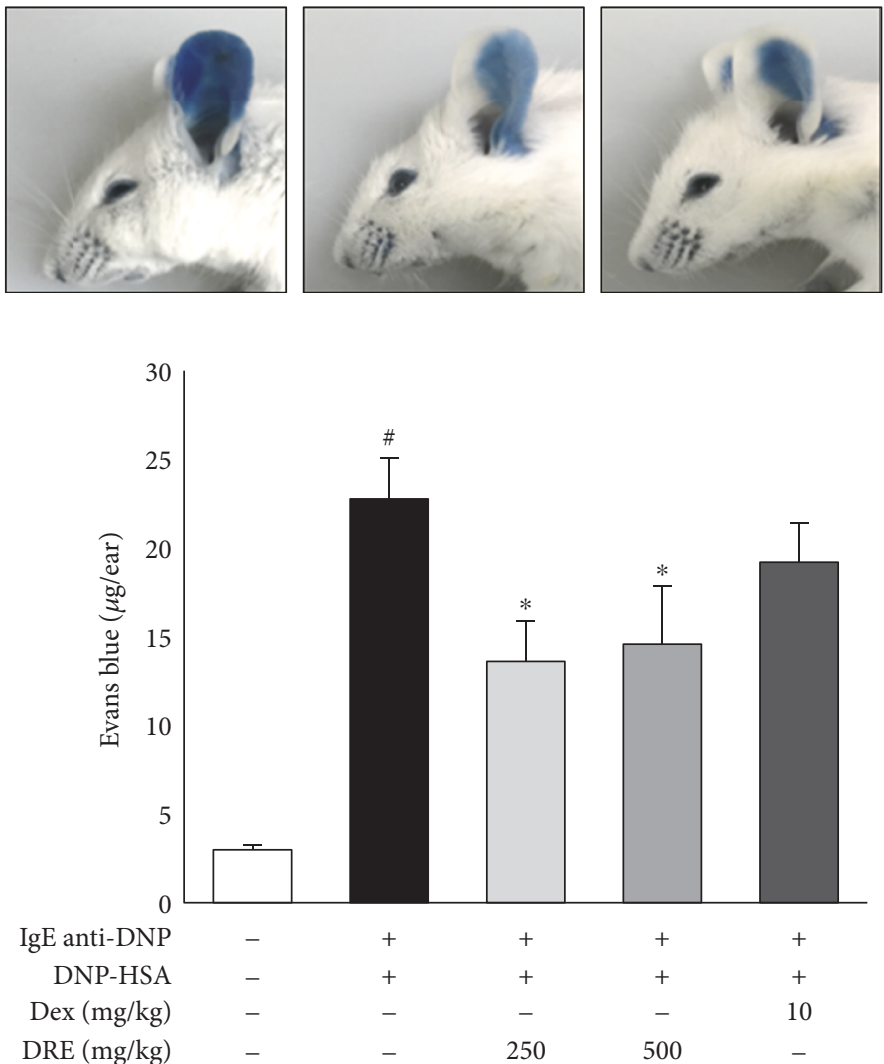

FIGURE 5: Effect of Drynaria rhizome extract (DRE) on the IgE anti-DNP/DNP-HSA-induced passive cutaneous anaphylaxis model. ICR mice were intradermally administered IgE anti-DNP $(4 \mu \mathrm{g} / \mathrm{mL})$ via the ear for $24 \mathrm{~h}$ and were then were orally administered DRE (250 or $500 \mathrm{mg} / \mathrm{mL})$ and dexamethasone $(10 \mathrm{mg} / \mathrm{mL})$. One hour later, DNP-HSA $(300 \mu \mathrm{g} / \mathrm{mL})$ containing $1 \%$ Evans blue was intravenously injected into their tail veins. After $1 \mathrm{~h}$, the extravasated dye in the ears was analyzed using the procedure described in Materials and Methods. Results are expressed as means $\pm \mathrm{SE}$ of at least five independent experimental results that were tested by analysis of variance with Bonferroni's post hoc testing; ${ }^{*} p<0.05$, the control group versus the DNP-HSA group; ${ }^{*} p<0.05$, the DNP-HSA group versus the DRE and Dex treatment-group.

is therefore predominantly used to study the IgE-FceRI interaction and the signal transduction pathways for the degranulation process [23].

In this study, we found that DRE prevented IgE-induced allergic responses and also observed remarkable reductions in degranulation. Degradation of granules in mast cells or basophils leads to the release of the enzyme $\beta$-hexosaminidase along with histamine. Therefore, this enzyme is often used as a marker of mast cell degranulation or histamine release [14]. Hexosaminidase assay is used to measure the efficacy of new drugs in preventing mast cell activation and degranulation [19]. Using this assay, we confirmed that DRE inhibited allergen-activated RBL-2H3 mast cell degranulation. Furthermore, DRE influenced allergic reactions, as shown by improvements in the concentrations of inflammatory cytokines. To elucidate the underlying mechanism, we evaluated the control of antiallergic effects and the expression of FceRI signaling-related genes known to influence the concentrations of inflammatory cytokines. Histamine released upon mast cell degranulation induces permeability hyperactivity, dilation of blood vessels, secretory action of secretory cells on mucosal surfaces, and a contraction effect on bronchial smooth muscles, leading to an immediate hypersensitivity reaction [24].

The results of the present study also demonstrated that histamine concentration decreased with DRE treatment. In addition, TNF- $\alpha$, IL-4, and IL- 6 secretion was inhibited in a concentration-dependent manner. The cytokines TNF- $\alpha$, IL-4, and IL- 6 are secreted mainly by T cells; they promote and sustain the inflammatory response, resulting in local and systemic effects in the human body $[25,26]$. TNF- $\alpha$ is a member of a growing family of peptide mediators and plays a crucial role in the pathogenesis of many acute and chronic inflammatory conditions. It is not only a potent inducer of other inflammatory cytokines, including IL-4 and IL-6, but it is also a self-secretory mediator [25]. IL-6 is involved in the growth and differentiation of $\mathrm{T}$ cells and $\mathrm{B}$ cells; it contributes to the proliferation of mast cells and is a type of inflammatory cytokine, a powerful mediator of inflammatory processes [27]. IL-4 also modulates the inflammatory response owing to its ability to affect adhesion molecule expression and cytokine production in endothelial cells; it 
promotes the growth and activation of neutrophils, mast cells, T cells, and eosinophils [26]. These observations suggest that DRE significantly inhibits mast cell degranulation and proinflammatory cytokine release.

One possible mechanism for DRE-induced antiallergic activity may be its effect on the FceRI signal cascade. IgEinduced mast cell degranulation is associated with FceRI receptor activation, which induces the release of various inflammatory mediators, including TNF- $\alpha$, leukotrienes, and prostaglandins via Lyn/Syk pathway phosphorylation [28]. Thus, Lyn and Syk are important intracellular mediators in early signaling following FceRI receptor activation [13]. In the present study, Syk was markedly inhibited by DRE, supporting the notion that it is a primary target of DRE. In turn, Syk activation increases MAP kinase family activation [29]. Further support of this observation was provided by the significant reduction in the phosphorylation of ERK1/2, p38, and Akt, which are downstream effectors of FceRI, by DRE [16]. Furthermore, DRE also inhibited COX-2 and $\mathrm{CPLA}_{2}$ expression and reduced the levels of the COX-2 product $\mathrm{PGD}_{2}$, which is enhanced in activated immune cells, including mast cells. The suppressive effects of DRE on $\mathrm{PGD}_{2}$ formation may contribute to its increased antiallergic activity, as $\mathrm{PGD}_{2}$ may mediate the inflammation associated with IL-4 [30]. These findings suggest that DRE reduces allergic reactions through the suppression of FceRI signal cascade and inhibition of the arachidonate signaling pathway.

We next examined how DRE suppresses IgE-mediated PCA in mice. PCA is characterized by an immediate skin reaction at a localized IgE-mediated allergic response in vivo, typically with increased vascular leakage in the skin that can be assessed by an intravenous injection of Evans blue [20]. In vivo, PCA can be identified based on ear swelling and skin color $[6,20]$. Consistent with in vitro findings, DRE successfully reduced allergic inflammatory responses in the PCA-induced mice. This result suggested that DRE inhibits IgE-mediated allergy responses by downregulating mast cell activation.

\section{Conclusions}

DRE has antiallergic effects in both IgE anti-DNP/DNPHSA-activated RBL-2H3 mast cells and IgE anti-DNP/ DNP-HSA-mediated PCA reactions. These antiallergic effects of DRE are because of the inhibition of the degranulation process and the production of allergenic mediators, such as histamine, TNF- $\alpha$, IL-4, IL- 6 , and $\mathrm{PGD}_{2}$, caused by antigen-IgE interaction. DRE may be a useful candidate for antiallergic drugs; because it is a natural product, it may be less toxic than current antiallergic drugs.

\section{Conflicts of Interest}

The authors declare no conflict of interest.

\section{Authors' Contributions}

Jin Yeul Ma and Kwang Il Park developed the study design and revised the manuscript. Hyun Ju Do participated in the study design, performed the experiments, analyzed the data, and wrote the draft manuscript. Tae Woo Oh and Ju Hye Yang performed the experiments and analyzed the data.

\section{Acknowledgments}

This work was supported by a grant (no. K17281) from the Korea Institute of Oriental Medicine funded by the Ministry of Education, Science and Technology (MEST), Republic of Korea.

\section{References}

[1] J. Ring, C. Akdis, R. Lauener et al., "Global allergy forum and second Davos declaration 2013 allergy: barriers to cure - challenges and actions to be taken," Allergy, vol. 69, no. 8, pp. 978-982, 2014.

[2] R. Pawankar, G. W. Canonica, S. T. Holgate, and R. F. Lockey, "Allergic diseases and asthma: a major global health concern," Current Opinion in Allergy and Clinical Immunology, vol. 12, no. 1, pp. 39-41, 2012.

[3] A. B. Kay, "Overview of 'allergy and allergic diseases: with a view to the future'," British Medical Bulletin, vol. 56, no. 4, pp. 843-864, 2000.

[4] J. N. Larsen, L. Broge, and H. Jacobi, "Allergy immunotherapy: the future of allergy treatment," Drug Discovery Today, vol. 21, no. 1, pp. 26-37, 2016.

[5] H. S. Shin and D. H. Shon, "Food and natural materials target mechanisms to effectively regulate allergic responses," Journal of Nutritional Science and Vitaminology, vol. 61, pp. S109S111, 2015.

[6] K. I. Park, D. G. Kim, J. M. Yoo, and J. Y. Ma, “The herbal medicine KIOM-MA128 inhibits the antigen/IgE-mediated allergic response in vitro and in vivo," Molecules, vol. 21, no. $8,2016$.

[7] J. C. Jeong, J. W. Lee, C. H. Yoon et al., "Stimulative effects of Drynariae Rhizoma extracts on the proliferation and differentiation of osteoblastic MC3T3-E1 cells," Journal of Ethnopharmacology, vol. 96, no. 3, pp. 489-495, 2015.

[8] W. Wang, H. Li, J. Yu et al., "Protective effects of Chinese herbal medicine Rhizoma drynariae in rats after traumatic brain injury and identification of active compound," Molecular Neurobiology, vol. 53, no. 7, pp. 4809-4820, 2016.

[9] J. C. Jeong, S. K. Kang, C. H. Youn et al., "Inhibition of Drynariae Rhizoma extracts on bone resorption mediated by processing of cathepsin $\mathrm{K}$ in cultured mouse osteoclasts," International Immunopharmacology, vol. 3, no. 12, pp. 16851697, 2003.

[10] Y. Y. Sung, D. S. Kim, W. K. Yang et al., "Inhibitory effects of Drynaria fortunei extract on house dust mite antigen-induced atopic dermatitis in NC/Nga mice," Journal of Ethnopharmacology, vol. 144, no. 1, pp. 94-100, 2012.

[11] S. J. Galli, "New concepts about the mast cell," The New England Journal of Medicine, vol. 328, no. 4, pp. 257-265, 1993.

[12] D. D. Metcalfe, D. Baram, and Y. A. Mekori, "Mast cells," Physiological Reviews, vol. 77, no. 4, pp. 1033-1079, 1997.

[13] J. P. Kinet, "The high-affinity IgE receptor (FceRI): from physiology to pathology," Annual Review of Immunology, vol. 17, pp. 931-972, 1999. 
[14] M. A. Gijon and C. C. Leslie, "Regulation of arachidonic acid release and cytosolic phospholipase A2 activation," Journal of Leukocyte Biology, vol. 65, no. 3, pp. 330-336, 1999.

[15] J. A. Mitchell, S. Larkin, and T. J. Williams, "Cyclooxygenase-2: regulation and relevance in inflammation," Biochemical Pharmacology, vol. 50, no. 10, pp. 1535-1542, 1995.

[16] W. Xiao, H. Nishimoto, H. Hong et al., "Positive and negative regulation of mast cell activation by Lyn via the FceRI," Journal of Immunology, vol. 175, no. 10, pp. 6885-6892, 2005.

[17] A. Mocsai, J. Ruland, and V. L. Tybulewicz, "The SYK tyrosine kinase: a crucial player in diverse biological functions," Nature Reviews Immunology, vol. 10, no. 6, pp. 387-402, 2010.

[18] A. Jiang, A. Craxton, T. Kurosaki, and E. A. Clark, "Different protein tyrosine kinases are required for $\mathrm{B}$ cell antigen receptor-mediated activation of extracellular signal-regulated kinase, c-Jun NH2-terminal kinase 1, and p38 mitogenactivated protein kinase," The Journal of Experimental Medicine, vol. 188, no. 7, pp. 1297-1306, 1998.

[19] O. Yodsaoue, S. Cheenpracha, C. Karalai, C. Ponglimanont, and S. Tewtrakul, "Anti-allergic activity of principles from the roots and heartwood of caesalpinia sappan on antigeninduced $\beta$-hexosaminidase release," Phytotherapy Research, vol. 23, no. 7, pp. 1028-1031, 2009.

[20] S. H. Lee, H. J. Shin, D. Y. Kim et al., "Streptochlorin suppresses allergic dermatitis and mast cell activation via regulation of Lyn/Fyn and Syk signaling pathways in cellular and mouse models," PLoS One, vol. 8, no. 9, article e74194, 2013.

[21] T. C. Theoharides and D. Kalogeromitros, "The critical role of mast cells in allergy and inflammation," Annals of the New York Academy of Sciences, vol. 1088, pp. 78-99, 2006.

[22] D. Zhu, C. L. Kepley, M. Zhang, K. Zhang, and A. Saxon, "A novel human immunoglobulin Fc $\gamma$-Fce bifunctional fusion protein inhibits FceRI-mediated degranulation," Nature Medicine, vol. 8, no. 5, pp. 518-521, 2002.

[23] W. Wang, Q. Zhou, L. Liu, and K. Zou, "Anti-allergic activity of emodin on IgE-mediated activation in RBL-2H3 cells," Pharmacological Reports, vol. 64, no. 5, pp. 1216-1222, 2012.

[24] K. D. Stone, C. Prussin, and D. D. Metcalfe, "IgE, mast cells, basophils, and eosinophils," The Journal of Allergy and Clinical Immunology, vol. 125, no. 2, Supplement 2, pp. S73-S80, 2010.

[25] C. A. Feghali and T. M. Wright, "Cytokines in acute and chronic inflammation," Frontiers in Bioscience, vol. 2, pp. d12-d26, 1997.

[26] M. A. Brown and J. Hural, "Functions of IL-4 and control of its expression," Critical Reviews in Immunology, vol. 17, no. 1, pp. 1-32, 1997.

[27] M. D. Turner, B. Nedjai, T. Hurst, and D. J. Pennington, "Cytokines and chemokines: at the crossroads of cell signalling and inflammatory disease," Biochimica et Biophysica Acta (BBA) - Molecular Cell Research, vol. 1843, no. 11, pp. 25632582, 2014.

[28] R. P. Siraganian, "Mast cell signal transduction from the highaffinity IgE receptor," Current Opinion in Immunology, vol. 15, no. 6, pp. 639-646, 2003.

[29] R. Xu, R. Seger, and I. Pecht, "Cutting edge: extracellular signal-regulated kinase activates syk: a new potential feedback regulation of Fc epsilon receptor signaling," Journal of Immunology, vol. 163, no. 3, pp. 1110-1114, 1999.

[30] K. Amin, "The role of mast cells in allergic inflammation," Respiratory Medicine, vol. 106, no. 1, pp. 9-14, 2012. 


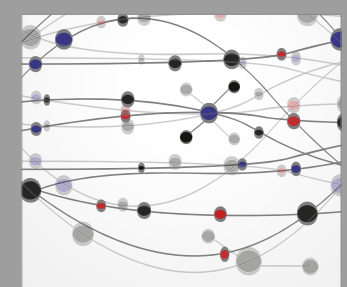

The Scientific World Journal
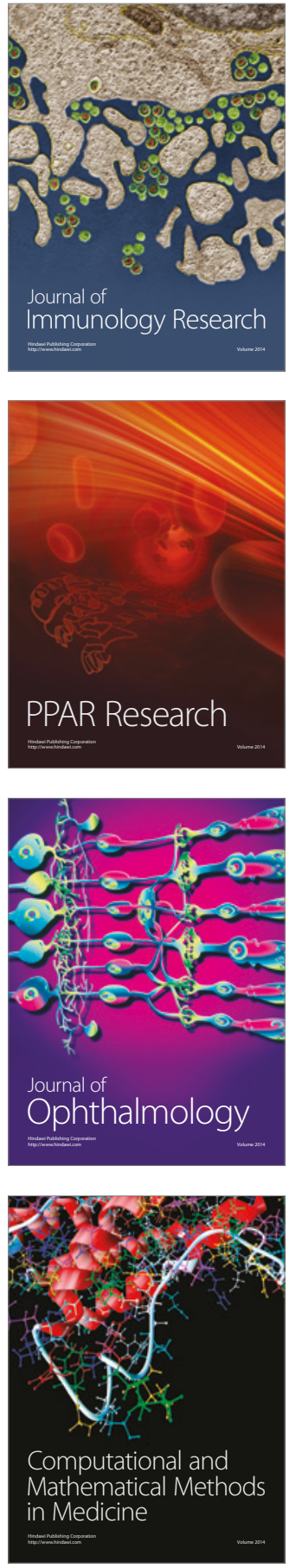

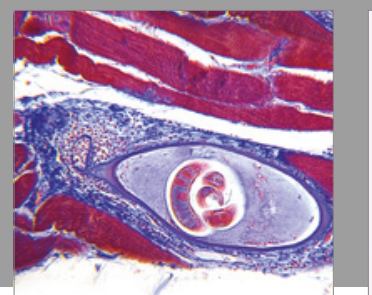

Gastroenterology Research and Practice
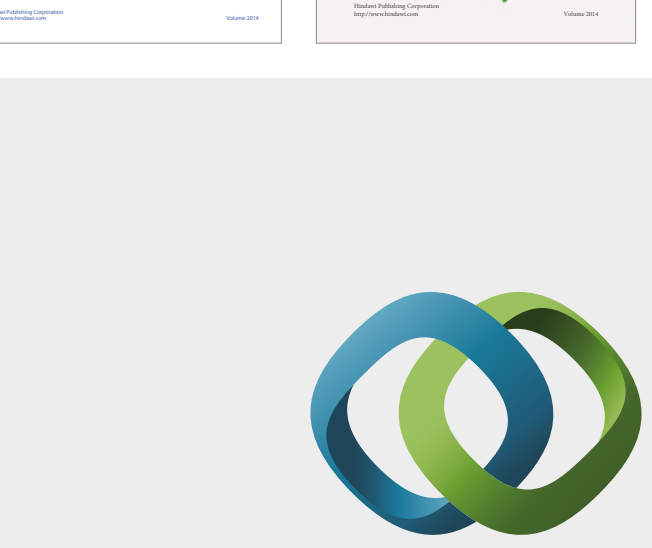

\section{Hindawi}

Submit your manuscripts at

https://www.hindawi.com
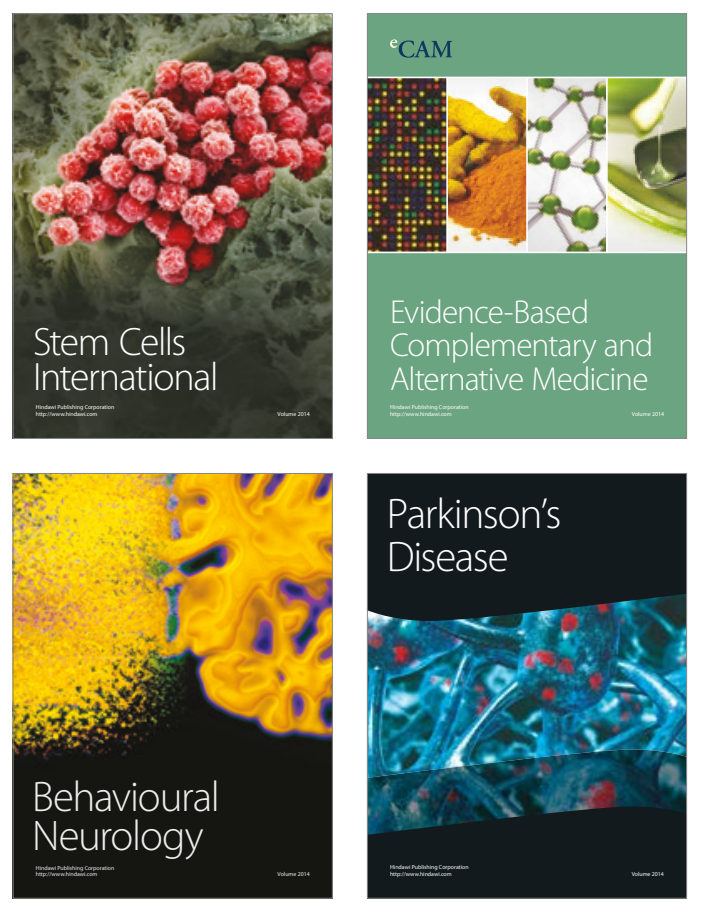
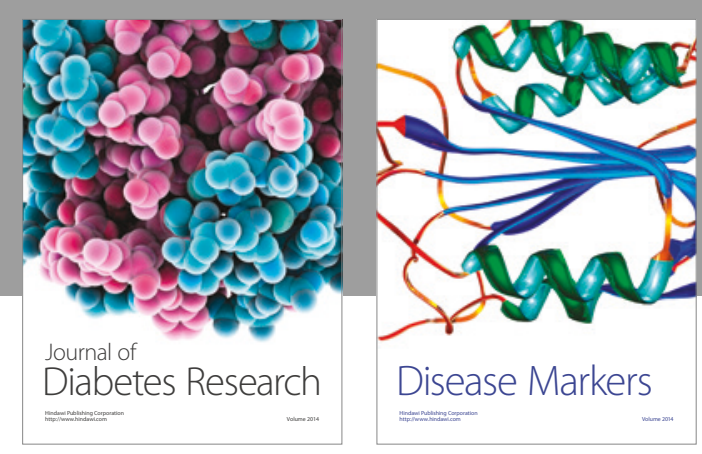

Disease Markers
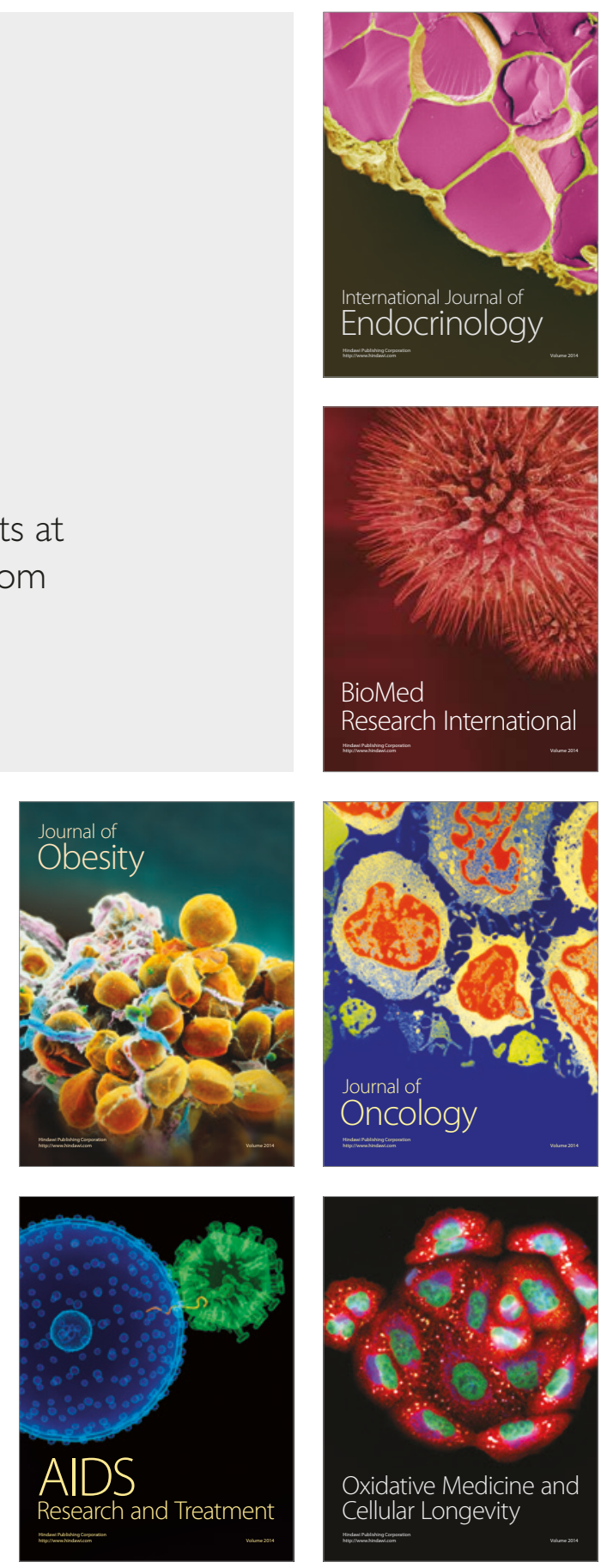